\title{
Repeated Thermal Therapy Upregulates Arterial Endothelial Nitric Oxide Synthase Expression in Syrian Golden Hamsters
}

\author{
Yoshiyuki Ikeda, MD; Sadatoshi Biro, MD; Yasuyuki Kamogawa, MD; \\ Shiro Yoshifuku, MD; Hideyuki Eto, MD; Koji Orihara, MD; \\ Takashi Kihara, MD; Chuwa Tei, MD
}

\begin{abstract}
It has been previously reported that sauna therapy, a thermal therapy, improves the hemodynamics and clinical symptoms in patients with chronic heart failure and also improves endothelial function, which is impaired in such patients. The present study investigated whether the improvements observed with sauna therapy are through modulation of arterial endothelial nitric oxide synthase (eNOS) expression. Eight male Syrian golden hamsters underwent sauna therapy, using an experimental far infrared-ray dry sauna system, at $39^{\circ} \mathrm{C}$ for $15 \mathrm{~min}$ followed by $30^{\circ} \mathrm{C}$ for $20 \mathrm{~min}$ daily for 4 weeks. Control group hamsters were placed in the sauna system switched off at room temperature of $24^{\circ} \mathrm{C}$ for $35 \mathrm{~min}$. Immunohistochemistry found greater amounts of the immunoreactive products of eNOS in the endothelial cells of the aorta and carotid, femoral and coronary arteries in the sauna group than in the control group. Western blot analysis also revealed that 4-week sauna therapy significantly increased eNOS expression in aortas by $50 \%$ in 4 series of independent experiments with an identical protocol $(\mathrm{p}<0.01)$. In reverse transcription polymerase chain reaction assay, the eNOS mRNA in aortas was greater in the sauna group than in controls, with a peak at 1-week of sauna therapy (approximately 40-fold increase). In conclusion, repeated thermal therapy upregulates eNOS expression in arterial endothelium. (Jpn Circ J 2001; 65: 434-438)
\end{abstract}

Key Words: Endothelial function; Gene expression; Nitric oxide; Sauna therapy; Vasodilation

$\mathbf{P}$ eripheral perfusion is impaired in patients with chronic heart failure (CHF) because of progressive peripheral vasoconstriction, which leads to increased resistance and cardiac afterload and exercise intolerance!,2 The hemodynamic improvement produced by vasodilators, such as angiotensin-converting enzyme (ACE) inhibitors, provides great therapeutic benefit to these patients? Our previous study showed that taking a warm-water bath or a sauna, performed appropriately, also reduces cardiac preload and afterload, by inducing vasodilation of the systemic and pulmonary arteries and veins, in both patients with CHF and healthy subjects. We have investigated thermal vasodilation by sauna therapy, which is free of the effects of hydrostatic pressure, as a new nonpharmacologic therapy for patients with CHF, and have found that most patients had a good response to this therapy5 We recently discovered that one mechanism by which sauna therapy improves the peripheral circulation is by enhancing endothelial function.

Endothelium-derived nitric oxide (NO) regulates vascular function, including relaxation, and inhibition of smooth muscle proliferation, platelet aggregation, and leukocyte adhesion to endothelium?-8 In CHF, production of NO is reduced, and hence vasomotor tone and cardiac afterload increased ${ }^{9-11}$ because endothelial NO synthase (eNOS) is

(Received December 21, 2000; revised manuscript received January 29, 2001; accepted February 7, 2001)

The First Department of Internal Medicine, Faculty of Medicine, Kagoshima University, Kagoshima, Japan

Mailing address: Chuwa Tei, MD, The First Department of Internal Medicine, Faculty of Medicine, Kagoshima University, 8-35-1 Sakuragaoka, Kagoshima 890-8520, Japan. E-mail: chuwatei@med5. kufm.kagoshima-u.ac.jp downregulated!2,13 Sauna therapy, a thermal therapy, increases cardiac output and blood flow, resulting in an increase in shear stress, which upregulates expression of eNOS? so we hypothesized that repeated sauna therapy would upregulate eNOS. We used immunohistochemistry, Western blot analysis, and reverse transcription polymerase chain reaction (RT-PCR) assay in Syrian golden hamsters to determine whether sauna therapy modulates eNOS expression.

\section{Methods}

Animals and Sauna Therapy

Male Syrian golden hamsters (Japan SLC, Hamamatsu, Japan) underwent sauna therapy in an experimental far infrared-ray dry sauna system (Kyushu Olympia, Miyazaki, Japan) at $39^{\circ} \mathrm{C}$ for $15 \mathrm{~min}$, and then at $30^{\circ} \mathrm{C}$ for $20 \mathrm{~min}$. We had previously established that with this protocol the rectal temperature rises almost $1{ }^{\circ} \mathrm{C}$ and remains elevated for at least $20 \mathrm{~min}$, as shown in the clinical setting. All animals were allowed food and water ad libitum and maintained under controlled environmental conditions $\left(24^{\circ} \mathrm{C}, 12-\mathrm{h}\right.$ light/dark cycles). The study was carried out in accordance with the Guide for Animal Experimentation, Faculty of Medicine, Kagoshima University.

\section{Experimental Protocol}

Hamsters in the sauna group had a sauna daily for 4 weeks, whereas those in the control group were placed in the sauna system switched off for $35 \mathrm{~min}\left(24^{\circ} \mathrm{C}\right)$. On the day after the last (28th) sauna, the hamsters were weighed, killed and aortas, carotid and femoral arteries, and hearts 
Table 1 Effects of Sauna Therapy on Body and Heart Weight in Hamsters

\begin{tabular}{|c|c|c|c|c|c|c|c|}
\hline & \multirow[b]{2}{*}{$n$} & \multirow{2}{*}{$\begin{array}{c}\text { Age } \\
\text { (weeks) }\end{array}$} & \multicolumn{3}{|c|}{ Body weight } & \multirow{2}{*}{$\begin{array}{c}H W \\
(g)\end{array}$} & \multirow{2}{*}{$\begin{array}{c}H W / B W \\
(\%)\end{array}$} \\
\hline & & & $\begin{array}{l}\text { Before sauna } \\
(\mathrm{g})\end{array}$ & $\begin{array}{l}\text { After sauna } \\
(\mathrm{g})\end{array}$ & $\%$ gain & & \\
\hline \multicolumn{8}{|l|}{ Series 1} \\
\hline Control & 8 & 8 & $113 \pm 5$ & $132 \pm 5$ & $17 \pm 5$ & $0.37 \pm 0.02$ & $0.28 \pm 0.01$ \\
\hline Sauna & 8 & 8 & $114 \pm 8$ & $132 \pm 9$ & $16 \pm 2$ & $0.36 \pm 0.01$ & $0.27 \pm 0.02$ \\
\hline \multicolumn{8}{|l|}{ Series 2} \\
\hline Control & 8 & 13 & $160 \pm 6$ & $185 \pm 7$ & $16 \pm 2$ & $0.42 \pm 0.03$ & $0.23 \pm 0.02$ \\
\hline Sauna & 8 & 13 & $161 \pm 6$ & $185 \pm 9$ & $15 \pm 5$ & $0.44 \pm 0.02$ & $0.23 \pm 0.01$ \\
\hline \multicolumn{8}{|l|}{ Series 3} \\
\hline Control & 8 & 15 & $178 \pm 9$ & $199 \pm 16$ & $12 \pm 4$ & $0.47 \pm 0.03$ & $0.25 \pm 0.03$ \\
\hline Sauna & 8 & 15 & $180 \pm 8$ & $202 \pm 10$ & $14 \pm 4$ & $0.48 \pm 0.03$ & $0.24 \pm 0.02$ \\
\hline \multicolumn{8}{|l|}{ Series 4} \\
\hline Control & 8 & 15 & $180 \pm 9$ & $206 \pm 5$ & $14 \pm 5$ & $0.47 \pm 0.03$ & $0.25 \pm 0.03$ \\
\hline Sauna & 8 & 15 & $183 \pm 9$ & $203 \pm 13$ & $11 \pm 4$ & $0.47 \pm 0.00$ & $0.24 \pm 0.01$ \\
\hline
\end{tabular}

$\%$ gain, percentage of body weight gain; $H W$, whole heart weight; HW/BW, whole heart weight to body weight ratio. All values are given as mean $\pm S D$.

were harvested, rapidly frozen, and stored at $-80^{\circ} \mathrm{C}$. Four series of independent experiments were performed with the same protocol to quantify the eNOS expression by Western blot analysis.

\section{Temperature and Hemodynamic Measurements}

In a group of 5 additional hamsters, we measured the rectal temperature, using a Thermister thermometer (Sibaura, Tokyo, Japan), and systolic and diastolic blood pressure (SBP and DBP) and heart rate, using a Millar catheter pressure transducer (Millar Instruments, Houston, TX, USA) cannulated into the right carotid artery, immediately after anesthetization with pentobarbital sodium $(50 \mathrm{mg} / \mathrm{kg}$ ip $)$. Hemodynamic parameters were recorded on a computer using the Mac Lab system (AD Instruments, Castle Hill, NSW, Australia).

\section{Immunohistochemistry}

The labeled streptavidin biotin method was performed using a Histfine kit (Nichirei, Tokyo, Japan). Briefly, crosssections of arteries were incubated overnight with rabbit polyclonal eNOS antibodies (Santa Cruz Biotechnology, Santa Cruz, CA, USA), diluted 1:500, at $4^{\circ} \mathrm{C}$ and then incubated with biotinylated anti-rabbit IgG at room temperature for $30 \mathrm{~min}$. The specimens were developed with diaminobenzidine and counterstained with hematoxylin.

\section{Western Blot Analysis}

Protein Preparation We obtained sample proteins according to the method described previously! ${ }^{14}$ Briefly, crude homogenates of aortas suspended in a homogenizing buffer of $50 \mathrm{mmol} / \mathrm{L}$ Tris- $\mathrm{HCl}$ at $\mathrm{pH} 7.4,1 \mathrm{mmol} / \mathrm{L}$ EGTA, $1 \mathrm{mmol} / \mathrm{L}$ dithiothreitol (DTT), $1 \mu \mathrm{mol} / \mathrm{L}$ pepstatin $\mathrm{A}, 2$ $\mu \mathrm{mol} / \mathrm{L}$ leupeptin, and $1 \mu \mathrm{mol} / \mathrm{L}$ (p-amidinophenyl) methanesulfonyl fluoride were ultracentrifuged to collect the cytosolic fractions. The pellets were solubilized in a homogenizing buffer containing $10 \%$ glycerol and $20 \mathrm{mmol} / \mathrm{L} \mathrm{3-[(3-}$ chol-amidopropyl) dimethylammonino]-1-propanesulfonate and ultracentrifuged to extract the particulate fractions.

Western Blot Analysis Western blot analysis was performed using the NuPAGE Electrophoresis System (NOVEX, San Diego, CA, USA). Briefly, $10 \mu \mathrm{g}$ protein samples from either the cytosolic or particulate fractions were electrophoresed and transferred to a nitrocellulose membrane. The membrane was incubated overnight with rabbit polyclonal eNOS antibodies at $4^{\circ} \mathrm{C}$, diluted 1:1,000, and incubated with anti-rabbit $\operatorname{IgG}$ antibodies conjugated with horseradish peroxidase (Santa Cruz Biotechnology) at room temperature (dilution 1:1,000) for $30 \mathrm{~min}$. The bands were detected using an enhanced chemiluminescence detection kit (Amersham Pharmacia, Buckinghamshire, UK) and exposed to X-ray film. We confirmed that the amounts of proteins loaded on the gel were equal by Coomassie blue staining and quantified the densities of the bands by scanning densitometry using NIH image computer software (NIH, Bethesda, MD, USA).

\section{RT-PCR Assay}

Aortas were taken from each of 6 extra hamsters before the sauna therapy began and then on the day after 3-days', 1-week', 2-weeks', and 4-weeks' sauna therapy. Total RNA was extracted by the acid guanidinium thiocyanate-phenolchloroform method described previously 15 To adjust the volume of the RNA sample, diethylpyrocarbonate-treated water was added to a total volume of $10 \mu \mathrm{l}$ for $1 \mu \mathrm{g}$ of RNA, after which $1 \mu 1$ of random hexamers (Takara biochemicals, Otsu, Japan) was added and heated at $70^{\circ} \mathrm{C}$ for $2 \mathrm{~min}$. Then $5 \mu \mathrm{l}$ of $5 \times$ reverse transcriptase buffer $(250 \mathrm{mmol} / \mathrm{L}$ Tris- $\mathrm{HCl}$ at $\mathrm{pH} 8.3,375 \mathrm{mmol} / \mathrm{L} \mathrm{KCl}$, and $15 \mathrm{mmol} / \mathrm{L} \mathrm{MgCl} 2$; Gibco BRL, Grand Island, NY, USA), $2.5 \mu 1$ of $0.1 \mathrm{~mol} / \mathrm{L}$ DTT, $5 \mu 1$ of $2.5 \mathrm{mmol} / \mathrm{L} \mathrm{dNTPs}, 0.5 \mu 1$ of $200 \mathrm{U} \mu 1$ reverse transcriptase (Gibco BRL) and $1 \mu 1$ of ribonuclease inhibitor at 20 UA 1 (Takara biochemicals) were added. Reactions were incubated at $37^{\circ} \mathrm{C}$ for $60 \mathrm{~min}$ and then at $70^{\circ} \mathrm{C}$ for $5 \mathrm{~min}$. PCR was performed using a PCR kit (Takara biochemicals). Primers for eNOS and $\beta$-actin, used as a positive control, were synthesized according to sequences published previously!6,17 The primer for eNOS corresponded to 5'-TACGGAGCAGCAAATCCAC-3' (sense) and 5'-CAGGCTGCAGTCCTTTGAT-3' (antisense), and the primer for $\beta$-actin corresponded to 5'-GCATCCTCACCCTGAAGTACCCCA3' (sense) and 5'-ACTCGTCATACTCCTGCTTGCTGAT3' (antisense). PCR was performed in a total volume of 50 1 containing $1 \mu 1 \mathrm{cDNA}, 5 \mu 1$ of $10 \times \mathrm{PCR}$ buffer $(20 \mathrm{mmol} / \mathrm{L}$ Tris- $\mathrm{HCl}$ at $\mathrm{pH} 8.0,100 \mathrm{mmol} / \mathrm{L} \mathrm{KCl}, 0.1 \mathrm{mmol} / \mathrm{L}$ EDTA, 1 $\mathrm{mmol} / \mathrm{L}$ DTT, $0.5 \%$ Tween $20,0.5 \%$ Nonidet P-40 and $50 \%$ Glycerol), $0.2 \mathrm{mmol} / \mathrm{L}$ dNTPs, $0.4 \mu \mathrm{mol} / \mathrm{L}$ primers and $0.5 \mu 1$ of Taq DNA polymerase. The mixed samples were heated to $94^{\circ} \mathrm{C}$ for $150 \mathrm{~s}$ and then cycled as follows: denaturation at $94^{\circ} \mathrm{C}$ for $60 \mathrm{~s}$, primer annealing at $53^{\circ} \mathrm{C}$ for eNOS and $55^{\circ} \mathrm{C}$ for $\beta$-actin for $1 \mathrm{~min}$, and extension at $72^{\circ} \mathrm{C}$ for $1 \mathrm{~min}$ for 32 cycles. Final extension was at $72^{\circ} \mathrm{C}$ for 
Table 2 Effects of Sauna Therapy on Hemodynamics in Hamsters

\begin{tabular}{|c|c|c|c|}
\hline & Before & During & After \\
\hline \multicolumn{4}{|c|}{ Rectual temperature $\left({ }^{\circ} \mathrm{C}\right)$} \\
\hline 1st sauna & $35.4 \pm 0.2$ & $36.4 \pm 0.1^{\S}$ & $36.2 \pm 0.1^{\S}$ \\
\hline 28 th sauna & $35.5 \pm 0.4$ & $36.5 \pm 0.2^{\S}$ & $36.4 \pm 0.2^{\S}$ \\
\hline \multicolumn{4}{|c|}{ Heart rate (beats/min) } \\
\hline 1st sauna & $353 \pm 17$ & $364 \pm 29$ & $349 \pm 18$ \\
\hline 28th sauna & $335 \pm 31$ & $336 \pm 39$ & $323 \pm 25$ \\
\hline \multicolumn{4}{|c|}{ Systolic blood pressure $(\mathrm{mmHg})$} \\
\hline 1st sauna & $124 \pm 4$ & $123 \pm 3$ & $117 \pm 16$ \\
\hline 28th sauna & $114 \pm 6^{*}$ & $104 \pm 9^{\dagger}$ & $92 \pm 7 * \xi$ \\
\hline \multicolumn{4}{|c|}{ Diastolic blood pressure $(\mathrm{mmHg})$} \\
\hline 1st sauna & $85 \pm 4$ & $84 \pm 10$ & $81 \pm 13$ \\
\hline 28th sauna & $78 \pm 5^{*}$ & $70 \pm 10$ & $63 \pm 6^{* *+1}$ \\
\hline
\end{tabular}

Sauna therapy was performed in an experimental far infrared-ray dry sauna system at $39^{\circ} \mathrm{C}$ for $15 \mathrm{~min}$, and then at $30^{\circ} \mathrm{C}$ for $20 \mathrm{~min}$. Before indicates before $39^{\circ} \mathrm{C}$ sauna; During, at the end of 15 -min $39^{\circ} \mathrm{C}$ sauna; After, at the end of 20 -min $30^{\circ} \mathrm{C}$ sauna. ${ }^{*} p<0.05$ and ${ }^{t} p<0.01$ vs 1 st sauna, ${ }^{\ddagger} p<0.05$ and ${ }^{\S} p<0.01$ vs before sauna. All values are given as mean $\pm S D(n=5)$.

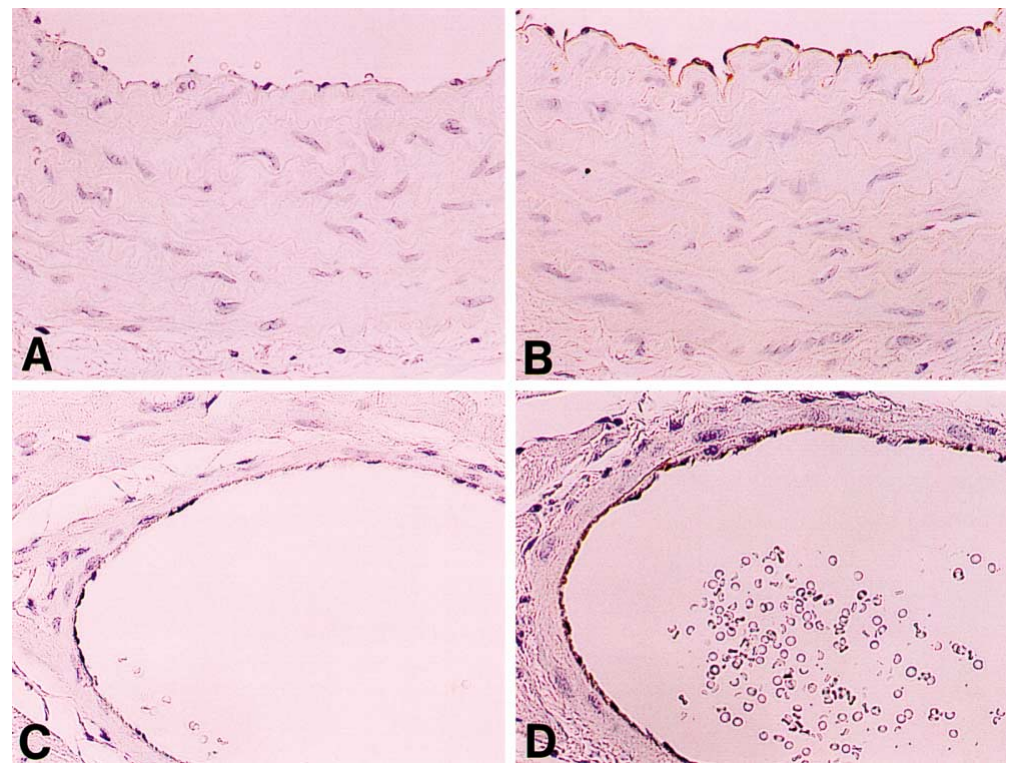

Fig 1. Immunoreactive products of eNOS were identified in the endothelial cells of arteries, and immunoreactivity was stronger in hamsters given sauna therapy than in untreated controls. Only minimal amounts of immunoreactive product were detected in the media and adventitia of either group. Aorta in (A) controls, (B) the sauna group; Coronary artery in (C) controls and (D) the sauna group $(\times 100)$.
7 min. PCR products were subjected to electrophoresis on a $1 \%$ agarose gel and then stained with ethidium bromide. The expected size of the eNOS PCR product was $819 \mathrm{bp}$, and that of $\beta$-actin was $906 \mathrm{bp}$, as in a preliminary study, we had found that these PCR cycles were within the linear phase of amplification. The quantity of the product was in proportion to the amount of cDNA used. The densities of the bands of the PCR products were estimated using NIH image computer software.

\section{Statistical Analysis}

All values are given as the mean $\pm \mathrm{SD}$, and statistical significance was set at $p<0.05$. Unpaired $t$ test was used for comparison between control and sauna group, and ANOVA was used for comparison of changes of hemodynamic parameters.

\section{Results}

\section{Body Weight, Temperature, and Hemodynamic Measurements}

There were no significant differences in the percentage of body weight gain and the ratio of whole heart weight to body weight between the 2 groups (Table 1 ). The rectal temperature of the hamsters rose by approximately $1{ }^{\circ} \mathrm{C}$ following a $15-\min 39^{\circ} \mathrm{C}$ sauna, and was maintained by a 20-min sauna at $30^{\circ} \mathrm{C}$ (Table 2). Heart rates did not show any change throughout the sauna nor between the first and 28th sauna. SBP and DBP did not change before or after the 1 st sauna, but the post-sauna pressures were lower than the pre-sauna pressures at the 28th sauna (Table 2). Furthermore, the SBP and DBP before the 28th sauna were lower than those before the 1st sauna (Table 2).

\section{Immunohistochemistry}

Immunoreactive products of eNOS were identified in the endothelial cells of aortas and coronary arteries in the control group, but the immunoreactivity was stronger in the sauna group than in the control group (Fig 1). The immunoreactive products were barely detectable in the media and adventitia of either group (Fig 1). These results were reproduced in each series. Immunoreactivity also increased in the endothelium of the carotid and femoral arteries.

Western Blot Analysis

Western blot analysis revealed that eNOS expression 
A

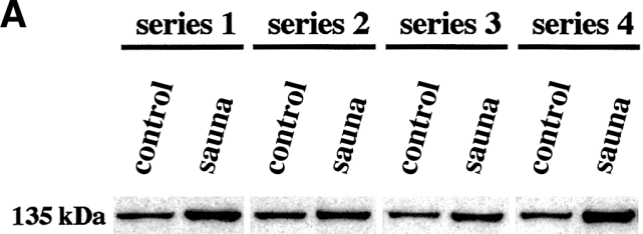

B

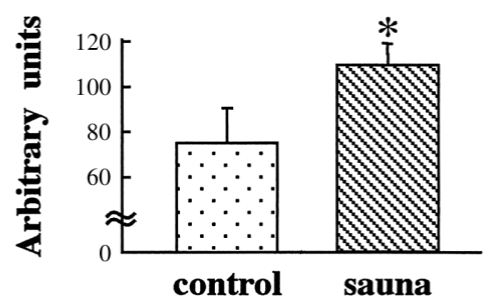

Fig 2. Western blot analysis. (A) eNOS expression was greater in the sauna group than in the control group. (B) Densitometric analysis of eNOS expression in sauna-treated hamsters and untreated controls. $* \mathrm{p}<0.05$ vs control.

$(135 \mathrm{kDa})$ was greater in the particulate fraction of aortas from the sauna group than in that from the control group (Fig 2A). Quantitative densitometric analysis confirmed that eNOS protein was significantly greater in the sauna group than in the control group $(109 \pm 10$ vs $74 \pm 16 n=8$, $\mathrm{p}<0.01$, Fig 2B). There was no difference between the 2 groups in the eNOS expression in the cytosolic fraction.

\section{RT-PCR Assay}

We next examined the expression of eNOS mRNA using RT-PCR (Fig 3). The eNOS mRNA in aortas, expressed as a percentage of $\beta$-actin, was greater in the sauna group than in the control group, with a peak at 1-week of sauna therapy. The amount of eNOS mRNA expression at 1-week of sauna therapy increased approximately 40 -fold in comparison with that in control group by densitometric analysis. The levels of RT-PCR products for $\beta$-actin did not differ throughout the 4-week sauna therapy.

\section{Discussion}

The present study clarified that repeated sauna therapy upregulates eNOS protein and mRNA in the arterial endothelium by immunohistochemistry, Western blot analysis and RT-PCR assay. Several recent studies have established that the endothelium-dependent vasodilatory response is attenuated in CHF because of decreased NO production and increased degradation of NO9-11 Patients with CHF have reduced cardiac output and decreased peripheral blood flow, resulting in a decrease in shear stress, and it is thought that these changes decrease NO production and downregulate eNOS. Smith et al have shown that eNOS protein is markedly reduced in the thoracic aorta of dogs with pacing-induced heart failure ${ }^{12}$ and similar results have been reported in rats with heart failure $!^{3}$ The hemodynamic changes induced by sauna in the present study (Table 2) might have been caused by an increase in NO production in vessels, such as the aorta and carotid, femoral and coronary arteries, thus decreasing cardiac afterload, increasing cardiac output and coronary flow, and improving the systemic hemodynamics, endothelial function and cardiac function. In our clinical study, repeated sauna therapy reduced clinical symptoms in

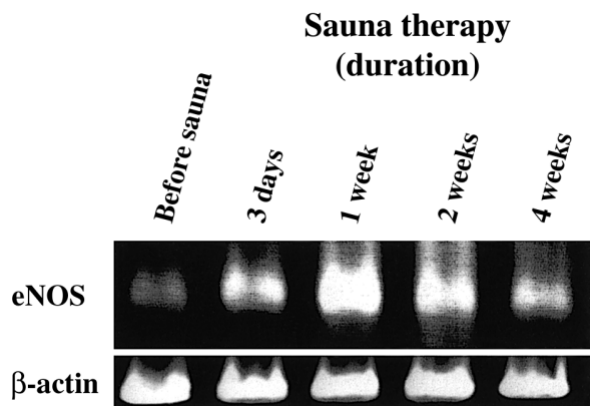

Fig 3. RT-PCR assay of eNOS and $\beta$-actin. The eNOS mRNA expression in aortas increased by sauna therapy, whereas $\beta$-actin mRNA expression did not change. The eNOS mRNA expression at 1week of sauna therapy increased approximately 40 -fold in comparison with that in the control group by densitometric analysis.

patients with CHF and decreased plasma concentrations of brain natriuretic peptide, secondary to improved peripheral circulation (unpublished data).

ACE inhibitors decrease plasma angiotensin II and increase bradykinin concentrations and thus increase NO bioavailability 18 Interestingly, exercise has been reported to also improve endothelial function in patients with $\mathrm{CHF}^{19-21}$ and to normalize decreased eNOS expression in an animal model of $\mathrm{CHF}^{22,23}$ We believe that eNOS upregulation induced by sauna is caused by an increase in cardiac output and blood flow ${ }^{4}$ which in turn results in increased shear stress. It is possible that thermal stimulation upregulates arterial eNOS directly. Another possibility is the involvement of tumor necrosis factora (TNFa), because it downregulates eNOS expression ${ }^{24}$ However, the precise mechanisms remain to be determined.

Although the thermoregulatory mechanisms are quite different between humans and hamsters, we observed that blood flow in the aortas of hamsters significantly increased during sauna treatment, as demonstrated clinically in patients with heart failure and normal subjects? It is an important point whether sauna therapy was stressful, or harmful, to the hamsters, but is unlikely because heart rates did not change during the sauna therapy and there was no difference in body weight between the 2 groups at the end of the 4-week sauna therapy. Furthermore, careful observation ensured that the hamsters were kept calm, and were not excited or suffering, during the sauna therapy, so their behavior was quite similar to that of the control hamsters kept in the switched-off sauna system.

This study was performed in healthy animals, and the next step is to examine the effect of sauna therapy in animals with CHF.

\section{Acknowledgments}

This study was supported in part by a Scientific Research Grant (10838025) from the Ministry of Education, Science and Culture of Japan.

\section{References}

1. Cohn J: Abnormalities of peripheral sympathetic nervous system control in congestive heart failure. Circulation 1990; 82: I-59-I-67

2. Packer M: Abnormalities of diastolic function as a potential cause of exercise intolerance in chronic heart failure. Circulation 1990; 81: 
III-78-III- 86

3. The SOLVD Investigators: Effect of enalapril on survival in patients with reduced left ventricular ejection fractions and congestive heart failure. N Engl J Med 1991; 325: 293-302

4. Tei C, Horikiri Y, Park JC, Jeong JW, Chang KS, Toyama Y, et al: Acute hemodynamic improvement by thermal vasodilation in congestive heart failure. Circulation 1995; 91: 2582-2590

5. Tei $\mathrm{C}$, Tanaka N: Thermal vasodilation as a treatment of congestive heart failure: A novel approach. J Cardiol 1996; 27: 29-30

6. Moncada S, Palmer RM, Higgs EA: Nitric oxide: Physiology, pathophysiology, and pharmacology. Pharmacol Rev 1991; 43: 109-142

7. Moncada S, Higgs A: The L-arginine-nitric oxide pathway. $N$ Engl J Med 1993; 329: 2002-2012

8. Forstermann U, Nakane M, Tracey WR, Pollock JS: Isoforms of nitric oxide synthase: Functions in the cardiovascular system. Eur Heart $J$ 1993; 14: I-10-I-15

9. Drexler H, Hornig B: Endothelial dysfunction in human disease. $J$ Mol Cell Cardiol 1999; 31: 51-60

10. Katz SD: Mechanisms and implications of endothelial dysfunction in congestive heart failure. Curr Opin Cardiol 1997; 12: 259-264

11. Ferrari R, Bachetti T, Agnoletti L, Comini L, Curello S: Endothelial function and dysfunction in heart failure. Eur Heart J 1998; 19: G41-G47

12. Smith CJ, Sun D, Hoegler C, Roth BS, Zhang X, Zhao G, et al: Reduced gene expression of vascular endothelial NO synthase and cyclooxygenase-1 in heart failure. Circ Res 1996; 78: 58-64

13. Comini L, Bachetti T, Gaia G, Pasini E, Agnoletti L, Pepi P, et al: Aorta and skeletal muscle NO synthase expression in experimental heart failure. J Mol Cell Cardiol 1996; 28: 2241-2248

14. Ohashi Y, Kawashima S, Hirata K, Yamashita T, Ishida T, Inoue N, et al: Hypotension and reduced nitric oxide-elicited vasorelaxation in transgenic mice overexpressing endothelial nitric oxide synthase. $J$ Clin Invest 1998; 102: 2061-2071

15. Chomczynski P, Sacchi N: Single-step method of RNA isolation by acid guanidinium thiocyanate-phenol chloroform extraction. Anal
Biochem 1987; 162: 156-159

16. Resta TC, Chicoine LG, Omdahl JL, Walker BR: Maintained upregulation of pulmonary eNOS gene and protein expression during recovery from chronic hypoxia. Am J Physiol 1999; 276: H699-H708

17. Ohmi K, Shinoura H, Nakayama Y, Goda N, Tsujimoto G: Characterization of alpha 1-adrenoceptors expressed in a novel vascular smooth muscle cell line cloned from p53 knockout mice, P53LMAC01 (AC01) cells. Br J Pharmacol 1999; 127: 756-762

18. Hornig B, Kohler C, Drexler H: Role of bradykinin in mediating vascular effects of angiotensin-converting enzyme inhibitors in humans. Circulation 1997; 95: 1115-1118

19. Hornig B, Maier V, Drexler H: Physical training improves endothelial function in patients with chronic heart failure. Circulation 1996; 93: $210-214$

20. Katz SD, Krum H, Khan T, Knecht M: Exercise-induced vasodilation in forearm circulation of normal subjects and patients with congestive heart failure: Role of endothelium-derived nitric oxide. $J$ Am Coll Cardiol 1996; 28: 585-590

21. Hambrecht R, Fiehn E, Weigl C, Gielen S, Hamann C, Kaiser R, et al: Regular physical exercise corrects endothelial dysfunction and improves exercise capacity in patients with chronic heart failure. Circulation 1998; 98: 2709-2715

22. Wang J, Yi GH, Knecht M, Cai BL, Poposkis S, Packer M, et al: Physical training alters the pathogenesis of pacing-induced heart failure through endothelium-mediated mechanisms in awake dogs. Circulation 1997; 96: 2683-2692

23. Varin R, Mulder P, Richard V, Tamion F, Devaux C, Henry JP, et al: Exercise improves flow-mediated vasodilatation of skeletal muscle arteries in rats with chronic heart failure: Role of nitric oxide, prostanoids, and oxidant stress. Circulation 1999; 99: 2951-2957

24. Agnoletti L, Curello S, Bachetti T, Malacarne F, Gaia G, Comini L, et al: Serum from patients with severe heart failure downregulates eNOS and is proapoptotic: Role of tumor necrosis factor-alpha. Circulation 1999; 100: 1983-1991 